\title{
Response to Alinka E. Greasley \& Helen M. Prior: Mixtapes and turntablism: DJs' perspectives on musical shape
}

\author{
ED MONTANO[1] \\ RMIT University
}

\begin{abstract}
This commentary responds to some of the debates and issues raised by Alinka Greasley and Helen Prior's paper on DJing and musical shape. In particular, I focus on the use of technology by DJs, and how shifts within this domain are redefining the concept and associated skills of DJing. Technological change is having a significant impact on music production and distribution within contemporary electronic dance music culture. Tangible formats and their playback platforms are increasingly fading into the history of DJ culture, and have been replaced with computers and software. In the process, the physicality of DJing, and the values of authenticity this physicality informs, have been reframed and renegotiated in the discourse that circulates within dance music culture. I suggest that Greasley and Prior's work provides a solid foundation for further investigations into not only the specifics of DJing and shape, but also the broader technological, social and cultural contexts of DJing as a contemporary artistic practice.
\end{abstract}

Submitted 2013 June 23; accepted 2013 June 28.

KEYWORDS: DJs, musical shape, technology, electronic dance music

THE increasing prominence of electronic dance music as a field of study has given rise to a variety of interesting research projects and debates. Alinka Greasley and Helen Prior's exploration of musical shape in DJing represents a significant addition. With much of the literature on DJs taking the form of historical overviews (see, for example, Bidder, 2001; Brewster \& Broughton, 2000; Fikentscher, 2000; Haslam, 2001; Lawrence, 2003; Phillips, 2009; Poschardt, 1998; Rietveld, 1998), or scene-specific analysis (e.g., Brennan-Horley, 2007; Gibson \& McGregor, 2011; Reitsamer, 2011; Weber, 1999), there remains much to be said on the practices and processes that underpin DJing as a contemporary form of artistic expression. This is not to say that DJ practice, as it relates to skills, techniques and technologies, has been overlooked (examples include Attias, 2011; Farrugia, 2012; Hadley, 1993; Herman, 2006; van Veen \& Attias, 2011, 2012), but rather that such focus on DJing as an artistic endeavour remains curiously underexplored. Explorations of this will aid our understanding of the way DJs harness particular technologies to create unique performance events that respond to the actions and reactions of clubbing audiences, as well as giving an insight into DJ mixing as a creative practice.

The overview of Prior's study of musical shape in classical performance provides some interesting contextual background for the analysis of DJs' perspectives on musical shape. This allows for insightful comparisons between the performance contexts of classical music and dance music (pp. 38-39), and highlights some of the similarities and differences between these contexts. While one may typically view the two worlds as polar opposites, the analysis of how shape is understood by participants in both styles demonstrates how shared principles and practices inform the performances of classical musicians and DJs. I found this a particularly enlightening section of the paper, and indeed, such comparisons are rarely made in published researched on DJing. I would, however, question the authors' claim in this discussion section that beat matching is "the most fundamental skill of DJ mixing" (p. 38). While it is certainly a central component, overemphasizing its importance overlooks the many DJs scattered throughout dance music history who placed little, if any, emphasis on the ability to sync records. Also, the importance of beat matching differs between sub-genres, with the seamless segues of progressive trance contrasting with the more fractured movement contained within drum and bass. The contrasting expectations around mixing in 
different styles would provide interesting case studies for further investigations into DJs' understandings of musical shape.

Further consideration could also be given to how shape is affected by the time that DJs are allocated to perform their sets. Greasley and Prior note that "Anecdotal evidence suggests that DJs like to take the listener 'on a journey' throughout a mix" (p. 39). The extent to which this can be fulfilled, however, depends on the duration of the DJ's set. The journey one can be taken on over the course of a three- or four-hour set would differ considerably from the journey delivered by a shorter set of sixty minutes. This is a significant issue due to the explosion in the number of dance music festivals in recent years (Montano, 2011). Sets at these festivals are typically of a far shorter duration than the time a DJ gets to play in a club, with shorter sets allowing for a more extensive festival line-up. However, if the principles and practices of DJing were founded upon notions of extended sets that lasted for several hours, during which DJs could take their audience on a journey, then condensing this into a smaller framework has implications not only for the experience the audience receives, but also for how DJs conceive and plan their sets, which brings into play notions of shape. A DJ will have to approach a truncated festival set with a different understanding of form and shape from the one they employ in an extended club set.

Given that DJing is a performance practice that is driven by the responses of the audience, the ability to react spontaneously is a key element of the DJ skill set. It is interesting to read the questionnaire responses of the female DJ (p. 25), who seems to invest considerable time in planning a set. This stands in contrast to some of the responses from DJs I have interviewed on the topic of planning versus spontaneity (Montano, 2009), who emphasized the importance of being able to adjust the flow of their music to the needs of the crowd. Of course, all DJs give consideration to what they will play prior to actually getting into the DJ booth, and so it is important not to paint DJing as entirely spontaneous. However, planning a set, and thus giving consideration to the arc and shape of this set, seems somewhat at odds with the idea of responding to audience reactions. This highlights a tension between planning and spontaneity that needs considering in further discussion of DJing and musical shape.

The calibre and experience of the DJs interviewed for the study are worth noting, and certainly lend credibility and authority to the research findings. I was particularly impressed with the inclusion of DJ Switch, a three-time winner of the World DMC Championship. One issue with the selection of the three DJs is that they all come from a background of performing music that emphasizes broken beats, working in styles such as drum and bass, hip-hop and electro swing. This is in contrast to the 'smoother' and 'four-tothe-floor' styles of house and trance. Despite the authors' identification of the DJs as "multi-genre" (p. 37), these are still DJs who operate within some very specific boundaries and who focus on some very specific techniques and performance styles, such as scratching. In dance music sub-genres such as house, scratching would be perceived as anathema for many DJs. Thus, while the limitations of the study prevent a more inclusive range of DJs from being used, I believe a degree of caution needs to be taken into account when considering the extent to which the findings are applicable to DJ practice as a whole. Arguably, understandings of musical shape in DJing within hip-hop culture would contrast markedly to such understandings within the trance scene, due to the different sonic moods and environments DJs in both styles seek to create. In further extended research on this topic, it would be interesting to compare and contrast understandings of musical shape across a variety of DJing contexts (club, bar, festival) and a variety of dance music styles (house, trance, techno, hip-hop).

The interview procedure, with its fusion of musical demonstration and discussion, is a unique approach that could, and indeed should, be implemented in future analyses of DJ practice. The use of different media to capture interview material allows for a thorough representation of responses. In this respect, capturing the gestural responses of the DJs when articulating their ideas on musical shape is particularly useful. The choice to utilize unfamiliar records in the demonstrations is an intriguing one. While I can see how it generated some interesting situations for discussion with the DJs of their approaches to mixing, it is important to note that DJs would rarely, if ever, play with unfamiliar records. Indeed, both Matt and Rich highlight how track familiarity informs their approach to DJing. As such, it is perhaps important to keep in mind that the research contexts presented here do not parallel the performing situations DJs are typically involved in.

Some of the discussion in this paper recalls the debates around the use of various playback platforms in DJ culture, some of which I have explored in my own research (Montano, 2010). With recent developments in technology and subsequent shifts in preferred formats for consuming music, DJing has 
become riddled with tensions around the use of vinyl, CDs, laptops and software such as Serato and Ableton. These tensions have been articulated through debates on what represents the 'authentic' skills of DJing, and on the different ways these skills are displayed in contexts of 'turntablism' and 'controllerism' (van Veen \& Attias, 2011, 2012). While I am unaware of any professional dance music DJs who continue to use vinyl within my field of research (the commercial electronic dance music scenes in Sydney and Melbourne), vinyl continues to be used by various DJs around the world, if not for nostalgic reasons then because the genre in which they perform places an emphasis on the format. For example, one would expect vinyl to figure somewhat more prominently in hip-hop DJ culture, with its focus on scratching (although that is not to say that scratching cannot be performed via digital technologies). The different 'feel' of digital technologies impacts upon the way DJs choose to engage with particular formats, while there are the various affordances of these technologies and formats, which subsequently impact upon the way clubbing crowds perceive the skills of a DJ.

While the use of software such as Serato maintains the tactility and physicality of vinyl mixing, with the shift away from tangible formats comes a shift away from visually engaging with the format as a means to inform the act of DJing. As Matt identifies (p. 32), the layout of the grooves on a record enables a DJ to make judgements on a track's sonic structure. With software, this visual inspection is replaced with a viewing of data on a computer screen, with the visualization of both individual tracks and the overall structure of the mix. This potentially allows for a more thorough engagement with the notion of shape, Rich identifying how the visualization of track waveform in Serato provides certain advantages when it comes to mixing tracks together (p. 33). This is further emphasized by Tony's description of a particular track's content in terms of "seeing" rather than "hearing" (p. 35). Prior to the development of this DJing software, any understanding of shape would have been conceived in a mostly abstract way in the mind of the DJ. Now, the visualization provided by the computer screen provides a concrete representation of sound. Potentially this could turn DJing into something based less on the selection and playing of tracks, and more centred on the live manipulation of sound. While the creative reworking of sound is not new for DJing (a simple setup of turntables and a basic mixer allowing the DJ to manipulate the bass and treble of tracks, for example), the use of digital audio workstations such as Ableton unlock the creative limitations of DJing and provide opportunities for a radical realignment of the skills associated with DJ culture.

\section{CONCLUSION}

Greasley and Prior's paper makes an important contribution to the developing field of electronic dance music studies, and more specifically to our understanding of DJing as both a profession and a cultural activity. Such understanding is important given the contemporary commercial explosion of electronic dance music, particularly in the U.S. DJs may once have been consigned to the dark corners of bars and nightclubs, but over the past two decades, with the development of the superstar DJ phenomenon, it is clear that the DJ is now one of the world's foremost cultural figures. DJs have become brand names, selling not only their club performances but also music, equipment and mix compilations. For Herman (2006, p. 31), "in a culture filled with brand names, the DJ is the ultimate brand name, the moniker under which almost everything is sold". Interrogating how DJs develop their skills and interpret their profession provides important insights into the way creativity and technology are negotiated within particular social and cultural domains. I look forward to reading the further research that will surely develop from Greasley and Prior's paper. Indeed, I have been inspired to re-activate my own investigations into DJ practice.

Greasley and Prior's work demonstrates that even if DJs do not typically think of their performances and mixes in explicit relation to 'shape', the concept is embedded within their approaches to DJing. It is just articulated through different terminology and conceptual frameworks, such as chaos, lack of skill, absence of beat-matching and "unlearning everything". Further investigations of DJing and shape could explore back-to-back performances (where two or more DJs play together) and how the presence of a co-performer impacts upon the shaping of the DJ set; the similarities and differences between understandings of shape in different dance music subgenres; and how shape is influenced by the time allocated for the DJ set (for example, a one-hour festival set in contrast to an eight-hour club set). Greasley and Prior's study provides a solid foundation on which to build these further explorations of DJing and shape. 


\section{NOTES}

[1] ed.montano@rmit.edu.au

\section{REFERENCES}

Attias, B.A. (2011). Meditations on the death of vinyl. Dancecult: Journal of Electronic Dance Music Culture, Vol. 3, No. 1. http://dj.dancecult.net/index.php/journal/article/view/96/138

Bidder, S. (2001). Pump Up The Volume: A History of House. London: Channel 4 Books.

Brennan-Horley, C. (2007). Work and play: Vagaries surrounding contemporary cultural production in Sydney’s dance music culture. Media International Australia, No. 123, pp. 123-137.

Brewster, B., \& Broughton, F. (2000). Last Night a DJ Saved My Life: The History of the Disc Jockey. London: Headline.

Farrugia, R. (2012). Beyond the Dance Floor: Female DJs, Technology and Electronic Dance Music Culture. Bristol: Intellect.

Fikentscher, K. (2000). “You Better Work!' Underground Dance Music in New York City. Hanover: University Press of New England.

Gibson, C., \& McGregor, A. (2011). The shifting spaces and practices of dance music DJs in Dunedin. In: T. Mitchell \& G. Keam (Eds.), Home, Land and Sea: Situating Music in Aotearoa New Zealand. Rosedale, Auckland: Pearson Education, pp. 206-215.

Hadley, D. (1993). 'Ride the rhythm': Two approaches to DJ practice. Journal of Popular Music Studies, Vol. 5, No. 1, pp. 58-67.

Haslam, D. (2001). Adventures on the Wheels of Steel: The Rise of the Superstar DJs. London: Fourth Estate.

Herman, B. D. (2006). Scratching out authorship: Representations of the electronic music DJ at the turn of the 21st century. Popular Communication, Vol. 4, No. 1, pp. 21-38.

Lawrence, T. (2003). Love Saves the Day: A History of American Dance Music Culture 1970-1979. London: Duke University Press.

Montano, E. (2009). DJ culture in the commercial Sydney dance music scene. Dancecult: Journal of Electronic Dance Music Culture, Vol. 1, No. 1, pp. 81-93.

http://dj.dancecult.net/index.php/journal/article/view/3/6

Montano, E. (2010). 'How do you know he's not playing Pac-Man while he's supposed to be DJing?': Technology, formats and the digital future of DJ culture. Popular Music, Vol. 29, No. 3, pp. 397-416.

Montano, E. (2011). Festival fever and international DJs: The changing shape of DJ culture in Sydney's commercial electronic dance music scene. Dancecult: Journal of Electronic Dance Music Culture, Vol. 2, No. 1, pp. 63-89. http://dj.dancecult.net/index.php/journal/article/view/45/99

Phillips, D. (2009). Superstar DJs: Here We Go! London: Ebury Press. 
Poschardt, U. (1998). DJ Culture. London: Quartet Books.

Reitsamer, R. (2011). The DIY careers of techno and drum ' $n$ ' bass DJs in Vienna. Dancecult: Journal of Electronic Dance Music Culture, Vol. 3, No. 1, pp. 28-43.

http://dj.dancecult.net/index.php/journal/article/view/77/126

Rietveld, H. (1998). This Is Our House: House Music, Cultural Spaces and Technologies. Aldershot: Ashgate.

van Veen, T.C., \& Attias, B.A. (2011). Off the record: Turntablism and controllerism in the 21 st century, part 1. Dancecult: Journal of Electronic Dance Music Culture, Vol. 3, No. 1.

http://dj.dancecult.net/index.php/journal/article/view/104/131

van Veen, T.C., \& Attias, B.A. (2012). Off the record: Turntablism and controllerism in the 21 st century, part 2. Dancecult: Journal of Electronic Dance Music Culture, Vol. 4, No. 1. http://dj.dancecult.net/index.php/journal/article/view/121/144

Weber, T. (1999). Raving in Toronto: Peace, love, unity and respect in transition. Journal of Youth Studies, Vol. 2, No. 3, pp. 317-336. 